\title{
Primary obstructed megaureter (POM) in children
}

\author{
Nagy $\mathrm{V}^{1}$, Baca $\mathrm{M}^{2}$, Boor $\mathrm{A}^{3}$ \\ Department of Urology, PJ Safarikiensis University, Medical Faculty and L Pasteur Teaching Hospital, \\ Kosice, Slovakia. vincent.nagy@upjs.sk
}

\begin{abstract}
The aim of this study was to analyze the results of surgical and conservative treatment of non-refluxing POM. In the period 2000-2009, 45 children (52 ureters) were treated, the average age was 5.8 months ( \pm 10.33 ), 24 children (26 ureters) by surgery (I) and 21 children ( 26 ureters) by conservative means (II). The average follow-up period was $73.8( \pm 32.91)$ and 30.85 months $( \pm 23.1)$ resp. Urine examination, USG, DTPA ${ }^{99 m T c}$, biochemical testing, micturating cystouretography in all patients were performed. Significant difference was present in the occurrence of hydronephrosis of 0 th, 3rd and 4th grade, $p<0.01$, or $p=0.17$; next in the occurrence of normal ureter, $0-5 \mathrm{~mm}$ and dilated ureter $>10 \mathrm{~mm}, \mathrm{p}<0.01$; and in the occurrence of normal and prolonged time $\mathrm{T} 1 / 2, p<0.01$. The health condition was adjusted in $13(54.20 \%)$, improved on DTPA $99 \mathrm{mT}$ in $5(20.85 \%)$, non-improved in $3(12.50 \%)$, deteriorated in 1 (4.15\%) and unknown in 2 (8.3\%) patients. In the Ilnd group a significant difference was in case of occurrence of hydronephrosis of 0 th, 2 nd and 3rd grade, $(p<0.01$, or $p=0.037$ and $p=0.011$ ) and in occurrence of normal ureter, with ureter $0-5 \mathrm{~mm}$ and dilated ureter $5-10 \mathrm{~mm}$, $p<0.01$. The condition at the end of the follow-up period was assessed DTPA ${ }^{99 m T c}$ as adjusted in 11 (52.39\%) patients, improved in $6(28.57 \%)$, unimproved in $3(14.28 \%)$ and no patient was assessed as having deteriorated and unknown in $1(4.76 \%)$.

Conclusion: In patients with an impaired separate kidney function, early surgical treatment helps to minimize damage to the kidney function and prevents future complications (Tab. 6, Fig. 3, Ref. 32). Full Text in PDF www.elis.sk. Key words: primary obstructed megaureter, cystouretography, hydronephrosis, kidney function, normal ureter.
\end{abstract}

This prospective study with systematically examined consecutive patients by a created protocol for both of the groups was aimed to compare surgical and conservative treatment of the primary obstructive megaureter (POM) in selected group of children. We present our view on the issue and the results of treatment in different groups of patients.

\section{Materials and methods}

In the Department of Urology in the Louis Pasteur University Hospital in Košice, between the years 2000-2009, we were treating 45 patients (52 ureters) with POM diagnosis. Patients' ages ranged between 1-63 months with the average of 5.8 months $( \pm 10.33)$. The clinical group was divided into the two groups according to the entrance criteria - that is group I - patients who were operated on and group II non-operated patients. We created a protocol for both of the groups on the basis of which we prospectively examined the patients, we were observing them and we evaluated the outcomes of the treatment. Within the methodology, we performed examination of the urine and urinary sediments,

${ }^{1}$ Department of Urology, PJ Safarikiensis University, Medical Faculty and L Pasteur Teaching Hospital, Kosice, Slovakia, ${ }^{2}$ Department of Urology, L Pasteur Teaching Hospital, Kosice, Slovakia, and ${ }^{3}$ Department of Pathology, L Pasteur Teaching Hospital, Kosice, Slovakia

Address for correspondence: V. Nagy, MD, PhD, Department of Urology, PJ Safarikiensis University, Medical Faculty and L Pasteur Teaching Hospital, Trieda SNP 1, SK-040 11 Kosice, Slovakia.

Phone: +421.55 .6403589 , Fax: +421.55 .6403603$ bacteriological examination of urine, in order to indicate the degree of dilatation of hydronephrosis and the width of the megaureter by USG of the kidneys and ureter, DTPA ${ }^{99 \mathrm{mTc}^{\mathrm{T}}}$ with the application of furosemide in order to detect the separated function of the kidney and time T1/2. As next step, we examined serum levels of natrium, potassium and chloride, urea and creatinine. At the beginning of the study, urography was performed in 12/45 (26.6 \%) individual cases because of unclear findings, and suspicion on another congenitally anomaly. This time we did urography generally in children extremely rare. Several patients underwent $\mathrm{x}$-ray retrogradual micturating cystouretography by urinary bladder catheterization in order to exclude secondary and refluxing megaureter. Patients were observed within interval of 3 to 6 months; two years later, we limited the observation to once per year. Hydronephrosis accompanying POM was evaluated according to Hoffman's scale, which is used also by the Society for Fetal Urology, SFU: 1st degree: width of the renal pelvis up to $10 \mathrm{~mm}$, without dilatation of calyces; 2nd degree: width of the renal pelvis more than $10 \mathrm{~mm}$, without major dilatation of calyces; 3rd degree: width of the renal pelvis more than $10 \mathrm{~mm}$ with dilatation of calyces without reduction of renal parenchyma; 4th degree: marked dilatation of calyces with renal parenchyma reduction (9). The clear indications for the surgery were: higher degree of hydronephrosis (3rd and 4th degree) and dilatation of ureter more than 5-10 $\mathrm{mm}$, clinical symptomatology of obstruction of the upper urinary tract (e.g. urinary tract infection - UTI), lowered renographic parameters from DTPA ${ }^{99 \mathrm{mTc}}$, decline in the separate function of the affected kidney to less than $40 \%$, and an obstructive type of the 
renographic curve with $\mathrm{T} 1 / 2$ more than $20 \mathrm{~min}$. The clear indication for the conservative procedure and active observation was a lower grade of hydronephrosis (1st a 2 nd grade) and width of the ureter $<5 \mathrm{~mm}$, asymptomatic development accompanying higher grade of hydronephrosis without damage to separated function of the affected kidney and non-obstructive type of the renographic curve on DTPA ${ }^{99 \mathrm{mTc}}$. ATB treatment was indicated in case of UTI. Antibiotics were indicated prophylactically with the $3 \mathrm{rd}$ and $4^{\text {th }}$ grade of hydronephrosis while finding in the urine was negative, and before surgery. Megaureter was detected on prenatal USG in 8 (38.10\%), on postnatal USG in 11 (52.4\%) children, incidentally by an urological examination for phimosis by 1 (4.75\%) and in another individual (4.75\%) incidentally during general examination for anaemia. Within the $1^{\text {st }}$. group, 24 patients were operated (26 ureters) at the age of 2-64 months, on average 10.08 months $( \pm 16.27)$, from these $17(70.8 \%)$ were boys and 7 (29.17\%) were girls. POM was left-sided in $17(70.8 \%)$ children, it was rightsided in $5(20.83 \%)$ and on both sides in $2(8.33 \%)$. Megaureter was diagnosed on prenatal USG in $5(20.83 \%)$ and on postnatal USG in 14 (58.34 \%) patients. In 5 children (20.83\%) POM was diagnosed on the basis of clinical symptomatology. During the operation, we performed excision of the expanded ureter with the stenosis of the terminal section, six times with the modelling of the ureter according to Hendren and reimplantation mostly according to Paquin, twice according to Cohen. Within the IInd group of non-operated, 21 patients ( 26 ureters) were actively observed, at the age of 1-16 months with an average age of 3.14 months $( \pm 4.15), 17$ of them $(80.95 \%)$ were boys and $4(19.05 \%)$ of them were girls. The POM was left-sided in $8(38.10 \%)$, right-sided in $8(38.10 \%)$ and on both sides in $5(23.8 \%)$ patients. The indication for the change from conservative treatment to surgery was the presence of the clinical symptoms due to obstruction of the upper urinary tract, the grade of hydronephrosis was deteriorated and the dilatation of ureter deteriorated, deterioration of separated function during the observation by more than $10 \%$ and obstructive type of the renographic curve with $\mathrm{T} 1 / 2$ more than $20 \mathrm{~min}$ on DTPA $^{99 \mathrm{mTc}}$. The periods of observation of the children who were operated from 3-110 months, on average 73.8 months $( \pm 32.91)$. Two patients after operation ignored all medical checks, although they were given a written notice. Within the group consisting of 21 non-operated and actively observed patients (26 ureters), the period of observation was from 3-97 months on average 30.85 months $( \pm 23.10)$. Temporary percutaneous nephrostomy was performed on one patient, the indication was a decrease of the separated function of the affected kidney under $30 \%$ due to renal insufficiency. At the end of the observation period, we evaluated conditions as: 1) Adjusted (negative finding in the urine, $0-1$ st grade of hydronephrosis, normal renographic parameters, and $\mathrm{DTPA}^{99 \mathrm{mTc}}$ ). 2) Improved (negative finding in the urine, improved stage of the hydronephrosis, improved renographic parameters, and DTPA ${ }^{99 \mathrm{mTc}}$ ). 3) Non-improved, stabilised (negative finding in the urine, non-deteriorated, stabilised grade of the hydronephrosis, non-deteriorated, stabilized renographic parameter, and DT$\mathrm{PA}^{99 \mathrm{mTc}}$ ). 4) Deteriorated (positive finding in the urine, deteriorated grade of hydronephrosis, deteriorated renographic parameters). In order to test differences between the frequencies of the occurrence of individual parameters, we used $\chi^{2}$ test and in cases, when the frequencies of the occurrence were lower than 5, besides this, we also used Fisher-Yate's correction, or Fisher's exact test. Qualitative variables are described by average value, the valuation of which is the arithmetic average and selective standard deviation. In order to test the hypothesis of equality of average values we used the unpaired $\mathrm{T}$ test. The differences we consider significant are those on significance level $p<0.05$. Patients with ipsilateral vesicoureteral reflux, and secondary megaureters in both groups were excluded from this analysis.

\section{Results}

\section{Group of surgically treated patients}

Within the group I consisting of 24 operated patients (26 ureters), $12(50 \%)$ patients were diagnosed with 4 th grade of hydronephrosis, thereof 1 time on both sides and $12(50 \%)$ patients were diagnosed with $3 \mathrm{rd}$ grade, thereof 1 time on both sides. In $5(20.85 \%)$ patients, the width of ureter was more than $5 \mathrm{~mm}$ and less than $10 \mathrm{~mm}$, thereof once on both sides. In 19 (79.15\%) patients, the width of ureter was more than $10 \mathrm{~mm}$, once on both sides. $14(58.3 \%)$ patients with confirmed POM, thereof seven with DTPA ${ }^{99 \mathrm{mTc}}$ and another seven with urography were indicated surgery treatment on the ground of clinical complications, i.e. due to deterioration of renal function, acute pyelonephritis, renal colic and persistent UTI. In 5 (20.8\%) patients, the surgery was indicated on the ground of diagnosed obstruction of megaureter by DTPA ${ }^{99 \mathrm{mTc}}$ with furosemide and with 3 patients $(12.5 \%)$ after urographical examination. Two patients who were operated on $(8.4 \%)$ underwent DTPA scan and urography. All of these patients were diagnosed with the 3rd and 4th grade of hydronephrosis (Tab. 1). Parameters observed in the group of surgically treated patients before the operation and at the end of the observation period are summarised in Table 2. Statistically significant difference before the surgery and at the end of the observation period was present in the occurrence of hydronephrosis of 0th, 3rd and 4 th grade, $\mathrm{p}<0.01$, or $\mathrm{p}=0.17$; next in the occurrence of no dilated ureter, $0-5 \mathrm{~mm}$ and dilated ureter $>10 \mathrm{~mm}, \mathrm{p}<0.01$; and in the occurrence of normal time $\mathrm{T} 1 / 2$ and prolonged time $\mathrm{T} 1 / 2, \mathrm{p}<0.0$, and better renal function. No statistically significant difference was found within the comparison of the separated function of kidneys. At the end of the observation period, the health condition was adjusted in 13 (54.20\%), improved on DTPA ${ }^{99 \mathrm{mTc}}$ in 5

Tab. 1. Group of surgically treated patients.

\begin{tabular}{lc}
\hline $\mathrm{n}=24$ & Number (\%) \\
\hline Degree of hydronephrosis 4 & $12(50)$ \\
Degree of hydronephrosis 3 & $12(50)$ \\
Width of the ureter $5-10 \mathrm{~mm}$ & $5(20.85)$ \\
Width of the ureter $>10 \mathrm{~mm}$ & $19(79.15)$ \\
Clinical symptomatology & $14(58.3)$ \\
Dynamic scintigraphy & $5(20.8)$ \\
Urography & $3(12.5)$ \\
Dynamic scintigraphy and urography & $2(8.4)$ \\
\hline
\end{tabular}


Tab. 2. Parameters observed in the group of surgically treated patients before operation and at the end of observed period $(n=24)$.

\begin{tabular}{|c|c|}
\hline Before operation & At the end of the observed period \\
\hline Age at the time of operation & Observed period \\
\hline 2-64 months & from 3 to 110 months \\
\hline average $10.08 \mathrm{SD} 16.27$ & average 73.8 months SD 32.91 \\
\hline \multicolumn{2}{|l|}{ Degree of hydronephrosis } \\
\hline 0th0 & 0th13(54.15\%) Improved $20(83.34 \%)$ \\
\hline 1 st 0 & 1st2 (8.3\%) Unchanged $1(4.16 \%)$ \\
\hline $2 \mathrm{nd} 0$ & 2nd1 (4.15\%) Deteriorated 0 \\
\hline $3 \mathrm{rd} 12(50 \%)$ & $3 \mathrm{rd} 4(16.65 \%)$ \\
\hline \multirow[t]{2}{*}{$4 \operatorname{th} 12(50 \%)$} & $4 \operatorname{th} 1(4.15 \%)$ \\
\hline & Unclassified $3(12.5 \%)$ \\
\hline \multicolumn{2}{|l|}{ Width of the ureter in $\mathrm{mm}$} \\
\hline $0-5: 0$ & 0-5: 16 (66.7\%) Improved: $19(79.17 \%)$ \\
\hline $5-10: 5(20.85 \%)$ & 5-10: 4 (16.6\%) Unchanged: $2(8.33 \%)$ \\
\hline \multirow[t]{2}{*}{$>10: 19(79.15 \%)$} & $>10: 1(4.2 \%)$ Deteriorated: 0 \\
\hline & Unclassified: $3(12.5 \%)$ \\
\hline \multicolumn{2}{|l|}{ Separated function } \\
\hline Standard: $9(37.5 \%)$ & Standard: 12 (50\%) Improved: 6 (25\%) \\
\hline Marginal: $1(4.2 \%)$ & Marginal 2 (8.33\%) Unchanged: $10(41.67 \%)$ \\
\hline \multirow[t]{2}{*}{ Damaged: $4(16.7 \%)$} & Damaged: $2(8.33 \%)$ Deteriorated: 0 \\
\hline & Unclassified: $2(8.33 \%)$ \\
\hline Unexamined:10 (41.6\%) & Not examined: $6(25 \%)$ \\
\hline \multicolumn{2}{|l|}{$T 1 / 2$} \\
\hline Standard: 0 & Standard:10 (41.7\%) Improved:11 (45.8\%) \\
\hline Marginal: $3(12.5 \%)$ & Marginal: $6(25 \%)$ Unchanged: $6(25 \%)$ \\
\hline Extended: $11(45.8 \%)$ & Extended: $2(8.3 \%)$ Deteriorated: $1(4.2 \%)$ \\
\hline Unexamined: $10(41.7 \%)$ & Unexamined: $6(25 \%)$ \\
\hline \multicolumn{2}{|l|}{ Finding in the urine: } \\
\hline Posit. $14(58.3 \%)$ & Posit.: 0 \\
\hline
\end{tabular}

\section{Creatinemy}

Standard: $23(95.8 \%)$ without deterioration during and at the end of the observation

Increased: $1(4.2 \%)$ with improvement after nephrostomy and at the end of observation

Tab. 3. Assessment of the state of surgically treated patients at the end of the observation period.

\begin{tabular}{lc}
\hline $\mathrm{n}=24$ & Number $(\%)$ \\
\hline Adjusted: & $13(54.20)$ \\
Improved: & $5(20.85)$ \\
Unimproved, stabilised: & $3(12.50)$ \\
Deteriorated: & $1(4.15)$ \\
Unclassified : & $2(8.30)$ \\
\hline
\end{tabular}

(20.85\%), non-improved stabilised in $3(12.50 \%)$, deteriorated in one (4.15\%) and unknown in $2(8.30 \%)$ patients (Tab. 3). Antibiotic prophylaxis was begun routinely in all patients surgically treated. Successful operated patients are presented on the Figures 1 and 2. Histological findings from the excised parts of ureters predominantly proved muscle fibrosis, chronic inflammatory cellulitis, and areas of fibrosis lapsing to hyalinosis, round-cell cellulitis, and tissue multiplification. Muscularis propria presented muscle sheaves with strips of collagen tissue consisting mostly of circularly aligned fibers and less often longitudinal muscle sheaves (Tab. 4) (Fig. 3). One patient at the age of 10 days diagnosed with hydronephrosis of the 4th grade with a functional solitary kidney and multicystic dysplasia of the collateral kidney with progression of renal insufficiency (creatinine in serum from
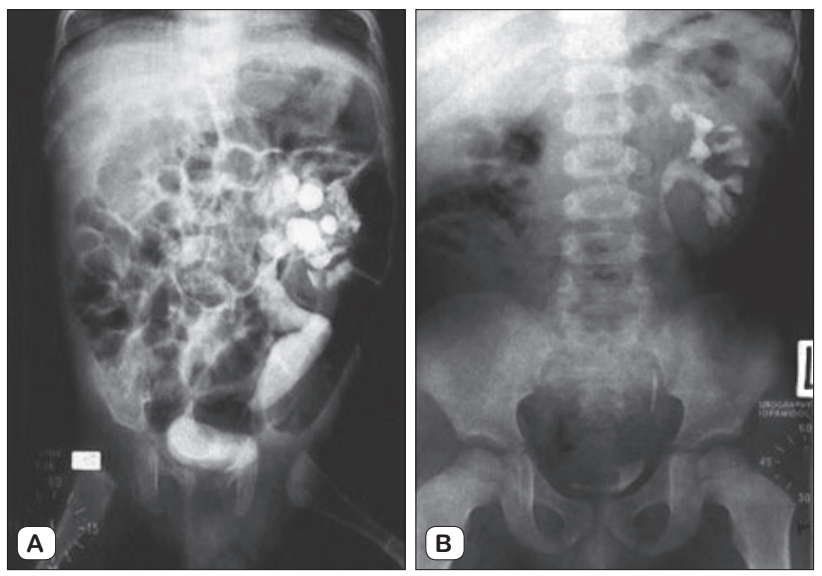

Fig. 1. IVU image before (A) and after the operation (B) of the obstructive megaureter in a solitary kidney.
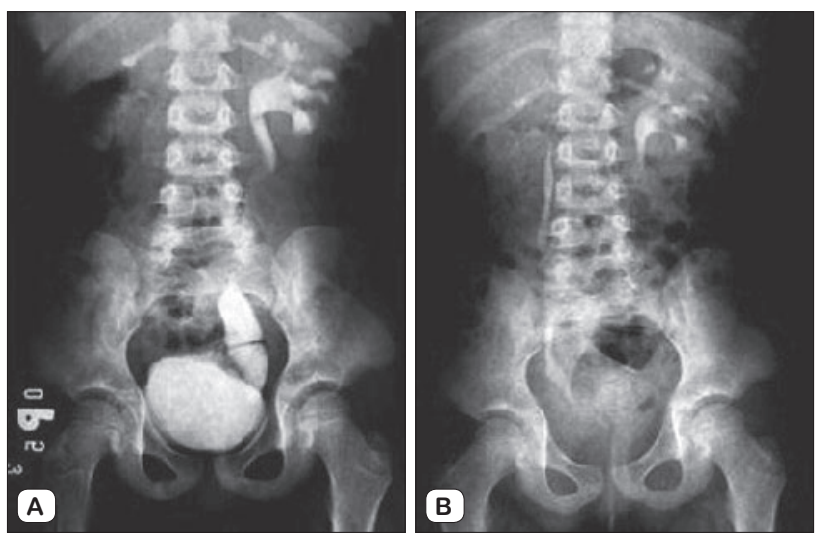

Fig. 2. IVU before (A) and after operation (B) of the left-sided obstructive megaureter.

197.5 to $261.6 \mu \mathrm{mol} / 1$, kalium in serum 6.5 to $4.9 \mathrm{mmol} / \mathrm{l}$, metabolic acidosis corrected by bicarbonates) underwent nephrostomy by punction followed by successive repair of metabolic disruption. He was operated after three months of urinary diversion via nephrostomy, currently with improved renal insufficiency. Three patients underwent reoperation (12.5\%), one of them underwent three operations altogether. The reasons for reoperation included the persisting hydronephrosis of 4th grade and the dilatation of ureter. Two out of three patients overcame acute pyelonephritis; the third patient with solitary kidney underwent reoperation two times. In two patients, the failure was due to stricture of ureterocystoneostomy after neoimplantation of ureter. One of the reasons

\section{Tab. 4. Histological examinations of excised ureters.}

\begin{tabular}{lc}
\hline $\mathrm{n}=24$ & Number (\%) \\
\hline Fibrosis of the muscle & $9(37.5)$ \\
Chronic inflammatory cellulitis, collagen tissue & $5(20.83)$ \\
Areas of fibrosis possibly lapsing to hyalinosis, and & $4(16.67)$ \\
round-cell cellulitis & \\
Fibrosis of the muscle and tissue multiplification & $4(16.67)$ \\
Muscle hypertrophy & $2(8.33)$ \\
\hline
\end{tabular}




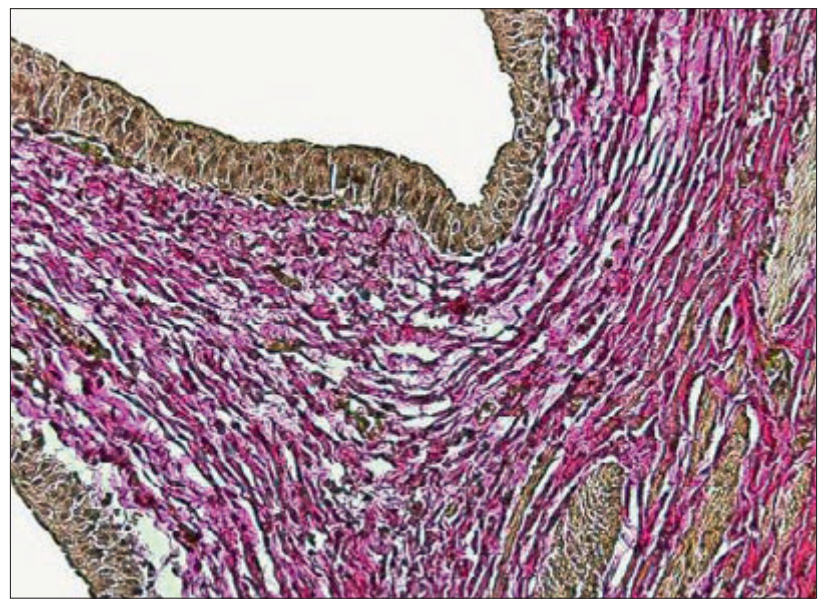

Fig. 3. Histopathological finding of an excised megaureter. HE. Magnification 400 times.

for reoperation was decompensation of obstructive megaureter with disturbed peristalsis that was not improved even after removal of the obstruction in the vesicoureteral conjunction. The same reasons were implied also with the third patient who was re-operated with the solitary kidney. At the end of the observation period, conditions of all patients were evaluated as unimproved, but stabilized. One patient, who underwent control examination

Tab. 5. Parameters observed in the group of conservatively treated patients at the beginning and at the end of the observed period $(n=21)$.

\begin{tabular}{|c|c|}
\hline At the beginning & At the end of observed period \\
\hline Age & Observed period \\
\hline $\begin{array}{l}1-16 \text { months } \\
\text { average } 3.14\end{array}$ & $\begin{array}{l}3 \text { to } 97 \text { months. } \\
\text { average } 38.15\end{array}$ \\
\hline SD 4.15 & SD 23.1 \\
\hline \multicolumn{2}{|c|}{ Degree of hydronephrosis } \\
\hline 0.0 & 0. 11 (52.39\%) Improved: 16 (76.19\%) \\
\hline $1.2(9.52 \%)$ & $1.4(19.05 \%)$ Unchanged: $3(14.29 \%)$ \\
\hline 2. $8(38.10 \%)$ & 2. 2 (9.52\%) Deteriorated: $1(4.76 \%)$ \\
\hline 3. $11(52.38 \%)$ & $3.3(14.28 \%)$ \\
\hline \multirow[t]{2}{*}{ 4. 0} & 4. 0 \\
\hline & Unclassified: $1(4.76 \%)$ \\
\hline \multicolumn{2}{|c|}{ Width of the ureter in $\mathrm{mm}$} \\
\hline $0-5: 0$ & 0 - 5: 14 (66.7\%) Improved: 17 (80.95\%) \\
\hline 5-10: $14(66.7 \%)$ & 5 -10: 4 (19.05\%) Unchanged: $3(14.29 \%)$ \\
\hline \multirow[t]{2}{*}{$>10: 7(33.3 \%)$} & $>10: 2$ (9.5\%) Deteriorated: 0 \\
\hline & Unclassified: $1(4.76 \%)$ \\
\hline
\end{tabular}

\section{Separated function}

Standard: 18 (85.72\%) $\quad$ Standard: 19 (90.48\%) Improved: 2 (9.52\%)

Marginal: $1(4.76 \%) \quad$ Marginal: 1 (4.76\%) Unchanged: 18 (85.72\%)

Damaged: $1(4.76 \%)$

Unexamined: $1(4.76 \%) \quad$ Unexamined: $1(4.76 \%)$

\section{$T^{1 / 2}$}

Standard: $9(42.86 \%) \quad$ Standard: $12(57.15 \%)$ Improved: 6 (28.57\%)

Marginal: $2(9.52 \%)$

Prolonged: $9(42.86 \%)$

Unexamined: $1(4.76 \%)$

Finding in the urine:

Posit.:5 (23.8\%) Posit.: 0

Creatinemy:

Standard: in all patients at the beginning and at the end of the observation
Tab. 6. Assessment of the state in the group of conservatively treated patients at the end of the observed period.

\begin{tabular}{lc}
\hline $\mathrm{n}=21$ & Number $(\%)$ \\
\hline Adjusted: & $11(52.39)$ \\
Improved: & $6(28.57)$ \\
Unimproved, stabilised: & $3(14.28)$ \\
Deteriorated: & $0(0)$ \\
Unclassified: & $1(4.76)$ \\
\hline
\end{tabular}

only after 6 years from the last examination in spite of repeated written calls, presented deterioration of kidney function with consequent nephrectomy.

Group of conservatively treated, non-operated and actively observed patients

The observed parameters in the group of non-operated patients at the beginning and at the end of the observed period are summarized in Table 5. Antibiotic treatment was given to 3 patients with UTI. Antibiotics were also given prophylactically in $10(47.6 \%)$ patients with the 3 rd grade of hydronephrosis, while finding in the urine was negative. A statistically significant difference at the beginning and at the end of the observation period was in case of occurrence of hydronephrosis of 0th, 2nd and 3rd grade $(\mathrm{p}<0.01$, or $\mathrm{p}=0.037$ and $\mathrm{p}=0.011)$ and in occurrence of non-dilated ureter, width of ureter $0-5 \mathrm{~mm}$ and dilated ureter $5-10 \mathrm{~mm}, \mathrm{p}<0.01$. During the observation of separated function on DTPA ${ }^{99 \mathrm{mTc}}$ and time $\mathrm{T} 1 / 2$ no statistically significant difference was detected. At the end of the observation period, the conditions of non-operated patients were adjusted in 11 (52.39\%), improved DTPA $^{99 \mathrm{mTc}}$ in $6(28.57 \%)$, unimproved, stabilized in $3(14.28 \%)$, deteriorated condition was not detected in any patient and in 1 (4.76\%) patient, it was impossible to assess the condition, as the patient was not cooperating (Tab. 6). A comparison of the conditions between surgically treated and non-operated patients at the end of observation period is demonstrated in Table 1. No statistically significant difference was observed. Statistically significant difference was observed in the occurrence of left-sided megaureter between surgically and conservatively treated patients, at the level of $\mathrm{p}<0.01$.

\section{Discussion}

Congenital anomalies of the urogenital system represent more than a third of all birth defects with 1.5 to $3.3 \%$ of incidence in all live births. The incidence of obstructed megaureter is 1 per 10.000 population. The male to female ratio is $1.2-4.8$ : 1 . Obstruction is bilateral in 10-20\% of cases of obstructed megaureter (17). The clinical significance of particular interest are anomalies associated with urinary tract obstruction and risk of renal impairment. These include the POM with a frequent lack of clinical symptoms, where in the lighter stage, there is the possibility of spontaneous recovery. Cure was explained by transient obstruction during fetal development of the ureter, which produces 4-6times greater than the amount of urine than after the birth. Consequently, it was assumed that surgical treatment would re- 
quire only about $10 \%$ of patients with POM (23). There is no doubt about indication of surgical treatment for this anomaly in POM of high level, in functional kidney damage or complicated UTI $(20,28)$. The management of the treatment of POM is still controversial. There's consent among urologists, that surgical correction is necessary in case of significant anatomical obstruction of POM, which is defined as a obstructive uropathy when the kidney exhibited stasis and large pelvic and caliceal dilatation $(19,26)$. On the other hand, when the kidney was subnormal or slightly dilated on urography (IVP), the patients were not operated on in the hope of a spontaneous improvement of the megaureter (19). However, there is also information concerning successful nonoperative treatment followed by spontaneous remission of this congenital anomaly. The problem lies within an exact identification of the significant blockage of the urine flow in ureter $(26,30)$. Koff defined an UPJ obstruction as "any restriction to urinary flow that, if left untreated, will damage kidney function..." (11), in our cases below $40 \%$. Probably, this definition can be used also in patients with POM (9). This is why an unreasonable waiting possibly causing permanent damage to the kidneys may not represent an acceptable method of treatment. Congenital defects of urogenital system can be detected by ultrasound as early as 15-17 weeks of gestation (13). This method of surveillance detects a significant fetal anomaly in $1 \%$ of pregnancies, of which $20-30 \%$ of cases are genitourinary in origin and $50 \%$ manifest as hydronephrosis. If not for prenatal USG detection, many of these urologic anomalies would manifest as they did in the past, later in life as pyelonephritis, symptomatic flank or abdominal pain, renal calculi, hypertension or even final-stage renal disease (15). In POM it is usually later, especially when the POM is associated with hydronephrosis. In our series of 45 children (52 ureters), we have antenatal with POM hydronephrosis diagnosed in $14(31.12 \%)$ patients, (in the Ist group - 5 surgically treated patients $(20.83 \%)$, which is significantly less than $79 \%$ (14). Postnatal USG was diagnosed with POM together in 24 cases (53.34\%) (In IInd group - 14 cases in no operated group of patients $(58.34 \%)$. In five children $(11.10 \%)$ was megaureter diagnosed after clinical manifestations of disease (1x abdominal pain, which caused an operational review of the presumed acute appendicitis, twice after pyelonephritis, twice for UTI). In one patient $(2.22 \%)$, the megaureter was diagnosed incidentally and in further patient $(2.22 \%)$ by random tests for other than urological reasons. The smaller number of prenatally diagnosed POM reflected the lack of investigation by prenatal ultrasound screening, which in recent years has steadily improved. The need to improve antenatal screening, but also examination in the postnatal period results mainly from the risk of serious damage to kidney function in the absence of any symptoms in the first months of life, what we observed in our series of patients. Diagnosis of upper urinary tract dilatation respectively kidneys is only the first step. Distinguish its causes was already possible in the postnatal period by now less widely used X-rays methods such as excretory urography and to exclude reflux with retrograde and voiding cystography (7). X-ray examinations we used more frequently in the past because we did not always have available later radionu- clide methods. At the present, the X-ray examinations are used in exceptional cases because of the high radiation load. In the tactics of treatment there is also applying the DTPA scan, diuretic scintigraphy with ${ }^{131}$ I-hippurate and ${ }^{99 \mathrm{~m}} \mathrm{Tc}-\mathrm{MAG} 3$ with furosemide $(10,31)$. This estimate of absolute renal function has been used to differentiate obstructive dilatations with implications for the renal parenchyma from those without. They can reliably determine the presence of obstruction of the upper urinary tract but also kidney function assessed separately, irrespective of serum creatinine level, which in children increases after decreasion of GFR below $50 \%$. For more frequent use of surgical treatment at POM, as it is now usual, we had two main reasons. The first was the fear of permanent damage to the kidneys at a higher degree of dilatation of the ureter and hydronephrosis and the second reason was our uncertainty on the basis of our experience with treatment, which concerns the possibility of spontaneous recovery ad integrum in another group of patients with the disease, which has its anatomical resp. morphological basis. This was confirmed by histological examination results, when in all children from the previous and present file in the distal part of the resected ureter the excessive substitution of muscle tissue by collagen tissue was found (Fig. 5). In our previous study in 4 (5.8 \%) from 69 children damage of renal function continued despite surgery and nephrectomy must be done (12). Therefore, as Peters et al (21) and Dvoracek et al (4), the conservative treatment was limited only to those patients where POM is associated with mild level of drain disorders and normal kidney function. In the indication for surgical treatment, it was necessary to resolve two major issues: at what age make a definitive treatment and surgical correction POM and when indicate a previous drainage upper urinary tract. It was clear that in neither issue we can take a strict opinion. We can accept the conventional wisdom that larger operations, unless indicated by the vital reasons, should not happen earlier than 3 month of life. This is also the age of our operated patients. Advantages of temporary drainage compare to definitive correction POM were fully confirmed in our previous study, whether in the treatment of pyelonephritis as well as decompression of the upper urinary tract with a significant reduction of the need for modeling at reimplanting (21). Concerning urinary diversion in obstructed megaureters in too young for surgery or in case of UTI there are in some cases for disposal or uretero-pyelocutaneostomy. Another possibility is the implementation of double J-stent - ureteral endoprosthesis $(22,32)$. For minimal invasiveness, ease and safety, however, we gave the priority in children with POM, like other authors, to percutaneous puncture nephrostomy $(19,5)$. Children with nephrostomy, if necessary and after informed consent of parents were without major problems regularly treated on outpatient basis. The most important question is to determine the presence of significant obstruction in the vesicoureteral junction (1) which if not treated, it leads to damage of kidney function. Surgical correction represented the standard therapy also in patients with incidentally discovered POM who did not present clinical symptoms of the disease (3). Spontaneous improvement of the POM in adults is rare and it already requires active surgical intervention (6). Surgical treatment was often limited to 
nephrourectomy, or after an operational correction, it was not able to completely repair the kidney function with persisting renal insufficiency (8). The main criterion for indication of surgical treatment is a decline in separated renal function at the beginning or at the end of observation (27). There is not a clear answer concerning ATB prophylaxis in actively observed patients with primary obstructed megaureter. There is no consent for prophylactic use of ATB if the urine finding proves to be sterile. Roth et al (25) reported low (4.3\%) occurrence of UTI in patients with hydronephrosis of 3rd or 4th grade by obstructive megaureter or obstruction in ureteropelvic junction. ATB prophylaxis in all asymptomatic patients with POM was not regarded as reasonable. Song et al (29) in patients with hydronephrosis of 3rd or 4th grade based on obstruction in ureteropelvic junction or POM a $36.2 \%$ incidence of the UTI was detected, in those who were not given ATB prophylaxis. Higher incidence (50\% vs $30.7 \%$ ), was in patients with POM in comparison with patients with obstruction in ureteropelvic junction. Accordingly, Baskin et al (3) published the results of long-term observations in patients originally reported by Keating (10), who were primarily treated conservatively. None of them presented deterioration of kidney function and deterioration of the degree of dilatation of kidney hollow system. Improvement of the degree of dilatation was present in $66.6 \%$ and finding stayed unchanged in $33.3 \%$ patients (2). Rickwood et al (24) confirmed the reliability of the active observation of patients with prenatally diagnosed megaureter, even in cases in which, according to renographic criteria, this seemed obstructive. We have reached, within groups of our patients treated in both ways - surgically and conservatively, results comparable to published data $(3,9,14,19)$. A conservative treatment was indicated in patients with a lower degree of hydronephrosis and dilatation of ureter. Dilatation of ureter of over $10 \mathrm{~mm}$ and decrease in function of afflicted kidney are prognostic factors for the necessity of surgical treatment (14), that is to say megaureters with diameter smaller than $10 \mathrm{~mm}$ are adjusted in easier and faster way (16). Hendren's reimplantations method, which was indicated in ureters with a diameter greater than $10-12 \mathrm{~mm}$, the drainage conditions treatment proved in all children. Assuming conservation of nourishing changes and suture tightness, we considered it to be safe and reliable method. Therefore, we have not seen the reason, if necessary, modelling the ureter. High benefit of surgical treatment, we have seen in particular that led to the high percentage of treated patients ad integrum with minimal incidence of serious complications.

\section{Conclusion}

The results of our study also with the smaller number of patients prove out the justness of the conservative treatment and active observation in patients with POM and lower level of the hydronephrosis and in patients with higher level of hydronephrosis without damage in the separated function in affected kidney without clinical symptoms of the complications linked to this disease. This enables avoiding overtreatment as well as to indicate an adequate surgical treatment in time. POM is a serious congenital anomaly with risk of permanent damage to kidney function. Patients with damaged separated kidney function or clinical symptoms and complications are indicated surgical treatment. By an early indicated surgical treatment, a kidney function damage is minimised, its growth potential is maximised and possible complications are thus prevented. However, it will be necessary to verify these results in a bigger group of patients in prospective, randomized studies.

\section{References}

1. Aksness G, Imaji R, Dewan PA. Primary megaureter: results of surgical treatment. ANZ J Surg 2002; 72: 877-880.

2. Apocalypse GT, Oliveira EA, Rabelo EA, Diniz JS, Marino VS, Pereira AK et a. Outcome of ureteropelvic junction obstruction identified by investigation of fetalhydronephrosis. Int Urol Nephrol 2003; 35 (4): 441-448.

3. Baskin LS, Zderic SA, Snyder HM, Duckett JW. Primary dilated megaureter: long-term followup. J Urol 1994; 152: 618-621.

4. Dvořáček J. Megaureters in children. Praha: ActaUniv Carol Med, 1998, 215p.

5. Dvořáček J et al. Urologie. II. Díl. Praha: IVS, 1998, 556-567.

6. Halachmi S, Pillar G. Congenital urological anomalies diagnosed in adulthood - management considerations. J Pediatr Urol 2008; 4 (1): $2-7$.

7. Hanna MK. http: //www.mkhanna.com/book.html.

8. Hemal AK, Ansari MS, Doddamani D, Gupta NP. Symptomatic and complicated adult and adolescent primary obstructive megaureter - indications for surgery: analysis, outcome, and follow-up. Urology 2003; 61 (4): 703-707.

9. Hoffman V. Ultraschalldiagnostik in Pädiatrie und Kinderchirurgie. Leipzig:VEB Georg Thieme, 1989.

10. Keating MA, Escala J, Snyder H McC, Heyman S, Duckett JW. Changing concepts in management of primary obstructive megaureter. $\mathrm{J}$ Urol 1989; 142 (2Pt 2): 636-645.

11. Koff SA. Problematic ureteropelvic junction obstruction, J Urol 1987; 138 (2): 390.

12. Kurcinová Z, Valanský L, Nagy V, Podracká L. Operative treatment of primary obstructive megaureter. Čes Urol 2000; 1: 18-21.

13. Lettgen B, Kroptfl D, Bonzel KE, Meyer-Schwickerath M, Rascher W. Primary obstructed megaureter in neonates. Treatment by temporary uretero-cutaneostomy. Br J Urol 1993; 72 (5).

14. Liu HY, Dhillon HK, Yeung CK, Diamond DA, Duffy PG, Ransley PG. Clinical outcome and management of prenatally diagnosed primary megaureters. J Urol 1994; 152 (2Pt 2): 614-617.

15. Liu DB, Edmondson JD. Antenatal hydronephrosis (2008). http:// emedicine.medscape.com/article/1016305-print.

16. McLelland DL, Retik AB, Bauer SB, Diamond DA, Atala A, Mandell J, Lebowitz RL, Borer JG, Peters CA. Rate and predictors of spontaneous resolution of prenatally diagnosed primary nonrefluxingmegaureter. J Urol 2002; 168: 2177-2180.

17. Mevorach, RA. (2009). http: //emedicine.medscape.com/article/441734-print. 
$650-656$

18. Merlini E, Spina P. Primary non-refluxing megaureters. J Pediatr Urol 2005; 1: 409-417.

19. Mollard P, Foray P, De Godoy JL, Valignat C. Management of primary obstructive megaureter without reflux in neonates. EurUrol 1993; 24: 505-510.

20. Mollard P, Foray P, De Godoy JL, Valignant C. Management of primary obstructive megaureter without reflux in neonates. Eur Urol 1993; 24 (4): 505-510.

21. Ottolenghi A, Campagnola S, Sulpasso M. Should primary megaureter be treated D 'Emblée in the neonate? Z Kinderchir 1988; 43: $154-155$.

22. Peters CA, Mandell J, Lebowitz RL, Colodny AH, Bauer SB, Hendren WH, Retik AB. Congenital obstructed megaureters in early infancy: diagnosis and treatment. J Urol 1989; 142: 641-645.

23. Ransley PG, Dhillon HK, Gordon I, Duffy PG, Dhillon MJ, Barratt TM. The postnatal management of hydronephrosis diagnosed by prenatal ultrasound. J Urol 1990; 144: 584-587.

24. Ransley P, Nijman RJM. Prenatalhydronephrosis and obstructive uropathy: therapeutic approaches. EBU Course Book 1998; 183-187.

25. Rickwood AMK, JEE LD, Williams MPL, Anderson PAM. Natural history of obstructed and pseudo- obstructed megaureters detected by prenatal ultrasonography. Br J Urol 1992 70: 322-325.
26. Roth CC, Hubanks JM, Bright BC, Heinlen JE, Donovan BO, Kropp BP, Frimberger D. Occurrence of urinary tract infection in children with significant upper urinary tract obstruction.Urology 2009; 73 (1): 74-78.

27. Shokeir AA, Nijman RJM. Primary megaureter: current trends in diagnosis and treatment. BJU International 2000; 86: 861-868.

28. Shukla AR, Cooper J, Patel RP, Carr MC, Canning DA, Zderic SA, Snyder HM. Prenatally detected primary megaureter: a role for extended followup. J Urol 2005; 173: 1353-1356.

29. Scholtmemeijer RJ. Treatment of the primary functional obstructive megaureter in childhood. Z Kinderchir 1989; 44: 345-347.

30. Song SH, Lee SB, Park YS, Kim KS. Is antibiotic prophylaxis necessary in infants with obstructive hydronephrosis? J Urol 2007; 177 (3): 1098-1101.

31. Stehr M, Metzger R, Schuster T, Porn U, Dietz HG. Management of the primary obstructed megaureter (POM) and indication for operative treatment. Eur J Pediatr Surg 2002; 12: 32-37.

32. Svitač J, Kliment J, Lepej J, Fetisov I. Diuretic scintigraphy with 131 I-hippurate and 99mTC-MAG3 in children with dilatation of the upper urinary tract. Bratisl Lek Listy 1993; 94 (5): 278-281.

33. Wilcox D, Mouriquand P. Management of megaureter in children. Eur Urol 1998; 34: 73-78. 